\title{
СОЦИАЛЬНАЯ ПОЛИТИКА
}

\section{Кадровая политика в здравоохранении: как преодолеть дефицит врачей}

\author{
И.М. ШЕЙМАН*, С.В. САЖИНА**
}

\begin{abstract}
*Игорь Михайлович Шейман - кандидат экономических наук, профессор, кафедра управления и экономики здравоохранения, Национальный исследовательский университет «Высшая школа экономики». Адрес: 101000, Москва, ул. Мясницкая, д. 20. E-mail: igor.sheim@g23.relcom.ru

**Светлана Владимировна Сажина - ведущий аналитик, Центр политики в сфере здравоохранения, Национальный исследовательский университет «Высшая школа экономики». Адрес: 109074, Москва, Славянская площадь, д. 4, стр. 2. E-mail: ssazhina@hse.ru
\end{abstract}

Цитирование: Шейман И.М., Сажина С.В. (2018) Кадровая политика в здравоохранении: как преодолеть дефицит кадров // Мир России. Т. 27. № 3. С. 130-153. DOI: $10.17323 / 1811-038 X-2018-27-3-130-153$

В статье анализируется взаимосвязь кадровой и образовательной политики в здравоохранении в решении задачи преодоления структурных диспропорций в составе медицинских кадров. Анализ зарубежного опыта показывает растущую ориентацию кадровой политики на достижение структуры врачебных кадров, соответствующей потребности системы здравоохранения и общества в целом. Развиваются новые механизмы планирования и регулирования структуры приема студентов медицинских вузов, а также структуры мест в системе постдипломного образования, включая квотирование приема студентов 8 медииинские вузы и на последипломную подготовку, регулирование трудоустройства подготовленных врачей, меры по сокращению дефиичта определенных категорий кадров и преодолению неравномерного географического размещения кадров.

В России структурная составляющая кадровой и образовательной политики явно ослаблена. Действующие методы планирования и регулирования подготовки медицинских кадров во многом воспроизводят накопленные структурные диспропорции; слабо выражены регулирующие меры повышения качества обучения врачей; отсутствует перспективное планирование. Последипломная подготовка врачей недостаточно ориентирована на дефицитные специальности, в результате чего при высоком числе врачей постоянно не хватает наиболее востребованных специалистов. В деятельности медицинских вузов прослеживается ориентация на подготовку врачей, обслуживающих платежеспособный спрос, при этом государство не обладает сильными рычагами влияния на структуру 
подготовки врачей. В последние годы предпринимаются попытки исправить положение путем установления новых требований к подготовке и переподготовке врачей, но пока результаты не ощущаются. Для снижения дефиџита врачей первичного звена выпускники вузов получают право на работу в качестве участковых врачей без последипломной подготовки, что может привести к снижению качества медицинской помощи. Базируясь на изучении зарубежного опыта, в статье предложены новые механизмы государственного регулирования подготовки врачей, включая изменение порядка планирования потребности во врачебных кадрах, повышение роли перспективного планирования, усиление регулирования структуры мест постдипломного обучения, повышение требований к его качеству.

Ключевые слова: здравоохранение, кадровая политика, образовательная политика, медицинское образование, врачи, последипломная подготовка

\section{Введение}

В последние годы в российском обществе заметно усилилось внимание к подготовке врачей, что связано прежде всего с общей неудовлетворенностью качеством обучения в медицинских вузах и низким уровнем компетенций выпускников. Состояние медицинского образования критикуют ведущие медики, организаторы здравоохранения [Ципенюк 2017] и даже министр здравоохранения В.И. Скворцова, назвавшая уровень подготовки врачей «бесстыдно низким» [Сквориова 2012], в том же ключе выступают и пациенты. В исследовании Левада-Центра, проведенном летом 2016 г., низкий профессиональный уровень врачей (на это указали 43\% респондентов) был назван второй по значению проблемой здравоохранения после длительных сроков ожидания медицинской помощи [Противостояние логик 2016]. Другая важная проблема медицинского образования - несоответствие его количественных и структурных характеристик потребности системы здравоохранения. В ряде исследований указывается на растущую ориентацию медицинских вузов на подготовку врачей «капитализируемых» специальностей, т.е. рассчитанных преимущественно на платежеспособный спрос, а также на недостаточную подготовку специалистов для массовой медицины в системе государственного здравоохранения; отмечаются дефицит врачей первичного звена здравоохранения и профицит многих категорий узких специалистов [Шейман, Шевский 2014; Шейман, Шевский 2015].

Основные характеристики кадровых ресурсов во многом закладываются в системе медицинского образования: они зависят от численности и структуры приема студентов в медицинские вузы, их выпуска, организации мест для последующего обучения в системе последипломной подготовки. Эти параметры определяются в рамках общей кадровой политики, понимаемой как «управление, планирование и мониторинг численности и состава профессиональных групп в здравоохранении на региональном, национальном и субнациональном уровнях» [Kuhlmann, Groenewegen, Batenburg, Larsen 2015]. Рациональная кадровая политика направлена на то, чтобы обеспечить соответствие численности и структуры подготовки кадров тому уровню, который диктуется потребностью системы здравоохранения, а в конечном счете - потребностями населения. 
В зарубежной литературе по организации и экономике здравоохранения особое внимание уделяется направлениям и механизмам влияния кадровой политики на систему медицинского образования. Можно акцентировать два наиболее крупных вопроса, активно исследуемых в работах западных специалистов. Первый включает в себя влияние планирования кадров, где рассматриваются направления и механизмы планирования, призванные обосновать количественные параметры приема студентов в медицинские вузы и их последующего обучения: например, изучаются общие тренды обеспеченности населения врачами и средним медицинским персоналом, выделяются перспективные сдвиги в составе кадров и определяются новые акценты в образовательной политике - приоритетная подготовка врачей общей практики, медицинских сестер с расширенным функционалом и т.д. [Birch, Kephart, Murphy, O'Brien-Pallas, Alder, MacKenzie 2009; Lafortune 2014]. Также рассматриваются аспекты улучшения качества планирования для обеспечения системы образования надежными оценками будущей потребности в кадрах [Ono, Lafortune, Schoenstein 2013; Batenburg 2015; Kuhlmann, Larsen 2015]. Другой вопрос кадровой политики - это регулирование состава студентов медицинских вузов и организаций постдипломного медицинского образования. В этом случае предметом анализа становятся конкретные механизмы этого регулирования и их способность реально обеспечить оптимальную структуру кадров; сравниваются практики отдельных стран, выделяются наиболее перспективные подходы [Lafortune, Moreira 2015; Ono, Schoenstein, Buchan 2014].

В российской литературе вопросы кадровой и образовательной политики обычно рассматриваются раздельно, хотя это взаимосвязанные направления государственного регулирования подготовки кадров. Если планирование и регулирование структуры кадров не учитывают в полной мере общественные потребности, то и образовательная политика «обречена» на воспроизводство нерациональной структуры подготовки кадров, т.е. медицинские вузы готовят не тех специалистов, которые в наибольшей мере востребованы системой здравоохранения.

В настоящей статье сделана попытка проведения такого комплексного анализа. Поставлена задача проследить влияние кадровой политики на формирование главных параметров подготовки врачей: сначала рассматриваются зарубежные подходы к планированию и регулированию кадрового состава отрасли, затем оценивается российская практика. Сравнение с зарубежными подходами дает основания для конкретных предложений по совершенствованию системы планирования и регулирования подготовки медицинских кадров. Методы исследования - аналитический обзор зарубежной и российской литературы, анализ показателей деятельности отдельных российских медицинских вузов на основе доступных данных в Интернете и статистический анализ.

\section{Зарубежный опыт}

В последние десятилетия в зарубежном здравоохранении наметились серьезные организационно-технологические сдвиги, которые диктуют необходимость изменения структуры врачебных специальностей, повышения стандартов вузовского и постдипломного обучения, ужесточения требований к сертификации на получение 
права ведения медицинской практики и к регламентации правил трудоустройства выпускников системы вузовского и послевузовского образования.

Медицинские вузы обладают значительной автономией в выборе обучающих программ и установлению требований к выпускникам. Образовательные стандарты разрабатываются и контролируются прежде всего профессиональным сообществом, заинтересованным в поддержании высокого статуса врача. Что же касается численности кадров и их распределения по специальностям и секторам здравоохранения, то эти вопросы в значительной мере являются предметом государственного планирования и регулирования. Эта тенденция связана с неспособностью рыночных механизмов обеспечить подготовку тех кадров, которые в большей степени соответствуют потребности системы здравоохранения и общества в целом. Известные в экономической теории провалы рынка (информационная асимметрия, неопределенность возникновения спроса) порождают явление «спроса, спровоцированного предложением», что выражается в расширении объемов медицинской помощи сверх рациональных потребностей, гипертрофированном развитии определенных специальностей, обладающих наибольшим потенциалом навязывания своих услуг. Информационная асимметрия, слабость ценового сигнала (в ситуации преимущественно государственного финансирования здравоохранения) не обеспечивают рыночное равновесие между спросом на определенные специальности и их предложением [Колосницьнна, Шейман, Шишкин 2009].

Усиление государственного вмешательства в определение численности и структуры врачей отражает также особенности современного этапа развития кадровых ресурсов в здравоохранении. Международные сравнения демонстрируют быстрый рост численности врачей в последние 1,5-2 десятилетия практически во всех странах ОЭСР, что позволило существенно улучшить показатель обеспеченности населения врачебными кадрами [Lafortune, Moreira 2015; Paris, Devaux, Wei 2010]. Но одновременно обостряется проблема структурных дисбалансов в составе кадровых ресурсов: по данным исследования Европейской Комиссии, например, во Франции ощущается нехватка акушеров и гинекологов, в Нидерландах - психиатров, гастроэнтерологов [Commission Staff Working Document 2012]. Особенно остро стоит вопрос о нехватке врачей первичной медицинской помощи. Доходы врачей общей практики в 1,5-2 раза ниже, чем доходы узких специалистов [Health at a Glance 2017], поэтому студенты неохотно осваивают эту специальность. В результате, например, в США лишь 10\% студентов медицинских вузов готовы стать врачами общей практики (хотя потребность в них быстро растет), и к 2025 г. ожидается нехватка 66 тыс. врачей первичной медицинской помощи, что составляет 29\% прогнозируемой общей численности врачей в стране [Gauld 2015].

Резко обострилась проблема неравенства в обеспечении отдельных территорий врачами и средним медицинским персоналом. Как следует из обзора, подготовленного специалистами ОЭСР, эта проблема существует практически во всех западных странах. Как в России, так и в западных странах врачи не склонны работать в сельских и удаленных районах, а также местах проживания бедного населения. Здесь ниже уровень доходов врачей, ощущается оторванность от ведущих медицинских центров и ниже стимулы для творческого развития [Ono, Schoenstein, Buchan 2014].

Наличие структурных диспропорций обусловило новые акценты в кадровой и образовательной политике. Вопросы экстенсивного наращивания численности 
врачей и медицинских сестер в последнее десятилетие постепенно уступают место проблемам формирования оптимальной структуры медицинских кадров, ориентированной на новые потребности системы здравоохранения [Lafortune 2014]. Это предполагает более активное вмешательство государства в определение пропорций подготовки кадровых ресурсов здравоохранения. В ряду главных направлений можно выделить:

- планирование приема студентов в медицинские вузы на основе оценок потребности в медицинских кадрах, проводимых органами государственного управления здравоохранением;

- регулирование состава постдипломного медицинского образования с акцентом на наиболее дефицитные врачебные специальности;

- контроль над трудоустройством выпускников медицинских вузов.

В большинстве западных стран определение количественных показателей приема в медицинские вузы и числа мест постдипломного образования опирается на систему кадрового планирования. Потребность в кадрах оценивается с учетом комплекса факторов, отражающих реальные потребности системы здравоохранения, включая демографические сдвиги в составе населения, уровни смертности и заболеваемости в разрезе отдельных заболеваний, объем потребления медицинской помощи, изменения в структуре здравоохранения. Комплекс учитываемых факторов постоянно расширяется, отражая процессы, идущие в самом здравоохранении: повышение роли первичной медицинской помощи, перемещение объемов медицинской помощи из стационаров в амбулаторные организации, растущее внимание к хронически больным, прогрессирующая производительность некоторых категорий специалистов. Планируется потребность в так называемых прочих категориях работников здравоохранения: специалистов по медицинской технике, информационным технологиям, медицинских инженеров, а также работников, обеспечивающих сервисные характеристики медицинской помощи, - при этом учитывается выбытие кадров в связи с более ранним выходом на пенсию врачей и медсестер. Показатели приема в медицинские вузы увязываются с финансовыми возможностями государства и населения [Шейман, Шевский 2015].

Особенно тщательно планируется потребность во врачах общей практики, которая растет в связи с универсальной тенденцией повышения доли хронических и множественных заболеваний [Muth, van den Akker, Blom, Mallen, Rochon, Schellevis, Becker, Beyer, Gensichen, Kirchner, Perera, Prados-Torres, Scherer, Thiem, van den Bussche, Glasziou 2014]. Население «доживает» до этих заболеваний, что диктует необходимость постоянного наблюдения за пациентами, координации и преемственности их лечения на разных этапах оказания медицинской помощи. Врачи общей практики превращаются в координаторов медицинской помощи, на этом уровне в большинстве европейских стран начинается и заканчивается лечение 85-95\% первичных обращений к врачу [Kringos, Boerma, Hutchinson, Saltman 2015], что в свою очередь выявляет необходимость установления разумной нагрузки для таких врачей. Главным показателем потребности системы здравоохранения в них является численность обслуживаемого населения: чем оно меньше, тем больше внимания будет уделено каждому пациенту. Соответственно, планы приема в ординатуру по общей врачебной практике определяются на основе плановых показателей нагрузки таких врачей. И что особенно важно, повышается роль перспективного планирования численности и структуры медицинских кадров. 
Существует значительный лаг во времени между принятием решения о численности приема студентов и фактической потребностью в кадрах, поэтому необходимо оценить эту потребность не на текущий момент, а в перспективе. Исследование методов планирования кадров в странах ОЭСР продемонстрировало, что в этих государствах в начале текущего десятилетия были разработаны перспективные планы численности врачей и среднего медицинского персонала до 2030 г., а в некоторых из них - и на более длительную перспективу, причем большинство этих планов детализированы по отдельным врачебным специальностям [Ono, Lafortune, Schoenstein 2013]. Такой подход дает медицинским вузам ориентиры для планирования количественных и структурных показателей приема студентов и организации всех этапов подготовки врачей.

В большинстве стран ОЭСР существенно укрепилась инфраструктура планирования: созданы центры планирования кадров в здравоохранении, расширилась их информационная база. Некоторые государства пошли по пути создания новых организаций: например, в США открыт Национальный центр анализа рабочей силы в здравоохранении, в Великобритании - Центр информации о рабочей силе. Эти организации имеют отделения в различных регионах и выполняют работы по заказу национальных и региональных органов управления, а также отдельных медицинских организаций [Ono, Lafortune, Schoenstein 2013].

В исследовании Е. Кульман и К. Ларсена под развитой системой планирования медицинских кадров понимается наличие планирующей организации, которая действует в центре и на местах, собирает большой объем информации по каждой специальности, использует модели, учитывающие факторы спроса и предложения рабочей силы, наделена правами определения количественных параметров развития кадровых ресурсов (т.е. планирующий орган не просто оценивает потребность в кадрах, но и обладает полномочиями по установлению квот приема студентов и структурных показателей их последующей подготовки) [Kuhlmann, Larsen 2015]. Авторы считают, что планирование кадров и приема студентов в медицинские вузы должно охватывать не только центральные органы власти (макроуровень планирования), но и регионы, а также медицинские организации и профессиональные группы (мезо- и микроуровень планирования). Только на такой основе можно обеспечить комплексность планирования с учетом многообразия факторов, определяющих потребность в медицинских кадрах. Планирование дополняется регулированием численности и структуры подготовки медицинских кадров. ОЭСР в своем исследовании по 29 странам, проведенном в 2008-2009 гг., выделяет пять механизмов такого регулирования [Paris, Devaux, Wei 2010]:

- квотирование приема студентов в медицинские вузы;

- квотирование структуры студентов по специальностям постдипломного образования;

- регулирование трудоустройства подготовленных врачей;

- меры по сокращению дефицита определенных категорий кадров;

- меры по преодолению неравномерного географического размещения кадров.

На сегодняшний день установление квот на прием в медицинские вузы (numerous clauses) действует во всех 29 странах. Особенно важно подчеркнуть, что квоты распространяются на все источники финансирования обучения - государственные и личные средства. В большинстве европейских стран, где 
доминирует государственное финансирование, число мест платного обучения также планируется с учетом установленных квот. Такой порядок исключает возможность искусственного наращивания числа мест по специальностям, которые востребованы студентами, но не соответствуют потребности системы здравоохранения.

Десять стран (в основном европейских) регламентируют и структуру подготовки врачей по отдельным специальностям. Важно подчеркнуть, что квотирование структуры врачебных кадров в этих странах направлено прежде всего на приоритетную подготовку врачей общей практики. Устанавливается доля мест постдипломного образования по соответствующей специальности: так, во Франции доля общей врачебной практики в общем числе мест в ординатуре в 2013 г. составляла $48 \%$, Канаде - 44\%, Англии - 40\%, США - 37\%, Финляндии - $19 \%$. В динамическом плане отмечается ускоренный рост подготовки врачей общей практики: например, во Франции, где вплоть до начала 2000-х гг. проводилась либеральная кадровая политика без попыток усилить первичное звено здравоохранения, число занятых мест постдипломной подготовки врачей общей практики в 2004-2013 гг. выросло в 2,7 раз (с 1200 до 3200), в то время как узких специальностей - только в 1,6 раза (с 2150 до 3400) [Lafortune, Moreira 2015].

В 21 из 29 стран ОЭСР, вошедших в обзор, проводится политика преодоления дефицита определенных категорий врачей. Ее важнейшим элементом является определение масштабов дефицита и профицита врачей определенных специальностей, при этом действующие методики определения дефицита не сводятся к определению числа незанятых вакансий. Имеющееся предложение кадров сравнивается с фактической или нормативной потребностью в кадрах определенной специальности, что дает возможность определить скрытую часть дефицита, связанную с работой по совместительству и чрезмерной нагрузкой врачей, также устанавливаются целевые показатели снижения разрыва между этими параметрами. Такая работа по преодолению дефицита планируется на несколько лет [Paris, Devaux, Wei 2010].

Увязка будущего места работы с попаданием в определенную категорию мест постдипломного образования. Например, во Франции наряду с жестким регулированием ординатуры по специальности «общая врачебная практика» также планируется число рабочих мест по этой специальности в конкретных территориях и медицинских организациях страны, и этот показатель соответствует приему студентов в ординатуру. Выпускники вузов, начинающие обучение в ординатуре, знают приблизительное место своей работы через несколько лет, но это не означает, что поступающий в медицинский вуз «обречен» на работу в качестве врача общей практики. После шести лет вузовского обучения проводится единый экзамен и составляется рейтинг выпускников. Право на свободный выбор специальности и места прохождения дальнейшей учебы имеют только лучшие студенты, оказавшиеся в верхних строчках рейтинга. Остальные должны продолжать обучение по общеврачебной подготовке (подчеркнем: продолжать обучение, а не практиковать). Эти меры не только регулируют географическое распределение врачей, но и обеспечивают приток медицинских кадров в первичное звено медицинской помощи.

Финансовое стимулирование. Приблизительно две трети стран ОЭСР используют финансовое стимулирование для регулирования географического распределения выпускников медицинских вузов. Помимо известных в российской практи- 
ке субсидий на обустройство врачей в сельской местности, используются также субсидии для укрепления врачебной практики (например, для найма помощников, способных заменить врачей на время их учебы или отдыха), ежегодные доплаты за стаж работы в удаленных районах, гарантии дохода врачей независимо от размера врачебной практики (государство доплачивает необходимую сумму в ситуации, когда врач общей практики не может набрать минимальное число обслуживаемых пациентов).

Регулирование локализачии врачебных практик позволяет определить территории с разной степенью обеспеченности врачами. Если в определенном районе обеспеченность врачами амбулаторной помощи выше средней по стране и отсутствуют основания для более высокой обеспеченности, то новые врачи уже не могут открыть здесь врачебную практику. Это делается для того, чтобы снизить мотивацию студентов к освоению узких специальностей, потребность в которых уже удовлетворена. Отметим, что речь идет о частной практике, именно она является объектом регулирования. В девяти стран ОЭСР ограничения распространяются только на тех врачей, которые работают по контрактам с органами государственного финансирования, остальные размещаются свободно (например, в Австрии), а в 11 странах ограничения на размещение врачебных практик носят универсальный характер.

Формирование более привлекательных условий для работы в сельской местности охватывает налаживание коммуникации между отдаленными врачебными практиками и крупными медицинскими центрами, стимулирование групповых форм работы, развитие телемедицины и службы экстренной помощи.

Таким образом, в большинстве западных стран государство активно влияет на структуру подготовки кадров, используя при этом разные механизмы.

\section{Российская практика планирования и регулирования подготовки кадров здравоохранения}

Россия является лидером по обеспеченности населения врачебными кадрами, однако мы постоянно сталкиваемся с дефицитом врачей разных специальностей. Наиболее сильно ощущается нехватка врачей первичного звена - это одна из наиболее важных проблем российского здравоохранения. Существуют многочисленные эмпирические доказательства высокой эффективности хорошо организованной первичной медицинской помощи: в странах с хорошо организованной общей врачебной практикой фиксируются относительно меньшие объемы специализированной помощи в расчете на одного жителя, низкие показатели общей смертности и смертности от наиболее распространенных заболеваний [Macinko, Starfield, Shi 2003; Starfield, Shi, Macinko 2005].

Между тем доля врачей участковой службы в общей численности российских врачей составляет всего 13\% (в Канаде и Франции - по 48\%, в Великобритании $29 \%$, в среднем по странам ОЭСР - 33\%) (таблища 1). Процесс специализации врачебных кадров, проявившийся в последние десятилетия во всех западных странах, в России выражен особенно сильно, что привело к острой нехватке врачей первичного звена. 
Таблица 1. Доля врачей участковой службы в общей численности врачей в отдельных странах в 2013 г., \% ${ }^{1}$

\begin{tabular}{|l|c|c|c|}
\hline Страна & Врачи участковой службы & Узкие специалисты & Всего \\
\hline Австралия & 50 & 50 & 100 \\
\hline Бельгия & 50 & 50 & 100 \\
\hline Франция & 48 & 52 & 100 \\
\hline Великобритания & 29 & 71 & 100 \\
\hline США & 40 & 60 & 100 \\
\hline Канада & 48 & 52 & 100 \\
\hline Германия & 43 & 57 & 100 \\
\hline Чехия & 19 & 81 & 100 \\
\hline Польша & 11 & 89 & 100 \\
\hline Венгрия & 26 & 74 & 100 \\
\hline Страны $О Э С \boldsymbol{P}$ & $\mathbf{3 3}$ & $\mathbf{6 7}$ & $\mathbf{1 0 0}$ \\
\hline Россия & $\mathbf{1 3}$ & $\mathbf{8 7}$ & $\mathbf{1 0 0}$ \\
\hline
\end{tabular}

Расчет на основе: [Health at a Glance 2017; Здравоохранение в России 2015].

Масштабы этого дефицита можно определить путем сравнения фактической и нормативной численности участковых врачей, которая устанавливается Минздравом России в виде показателя численности населения: один участковый терапевт должен обслуживать 1700 пациентов ${ }^{2}$, однако на практике нагрузка такого врача намного выше - в среднем 2622 чел. [Здравоохранение в России 2015]. Если сравнить фактическую нагрузку участковых терапевтов с нормативной, то получим оценку дефицита в размере $32 \%$; аналогичная оценка для участковых педиатров составляет $13 \%$.

Многократно провозглашенный курс на ускоренную подготовку врачей общей практики затянулся на десятилетия. Сегодня доля таких врачей в общей численности врачей участковой службы составляет лишь 13\% (9,5 тыс. против 71 тыс. - общей численности участковых терапевтов и педиатров, а также врачей общей практики), в то время как практически во всех странах Центральной и Восточной Европы удалось подготовить нужное количество таких врачей и на $100 \%$ укомплектовать участки первичной медицинской помощи [Шишкин, Шейман, Абдин, Боярский, Сажина 2017].

В ряду прочих диспропорций - профицит врачей в стационарах и дефицит в поликлиниках, острейшая нехватка врачей в сельской местности, низкое соотношение числа медсестер и врачей (два к одному против трех-пяти к одному в западных странах), слабое развитие смежных (немедицинских) специальностей, нерациональное соотношение между числом должностей и числом врачей -

1 Страны ОЭСР - врачи общей практики, Россия - участковые терапевты, участковые педиатры, врачи общей практики.

2 Пункт 18 Приказа Минздравсоцразвития России от 15.05.2012 № 543н. 
физических лиц с вытекающим отсюда высоким совместительством [Шейман, Шевский 2014]. Доля занятых врачебных должностей стационарного сектора в общем числе врачебных должностей в период 1995-2012 гг. выросла с 45,2 до 47\%, при этом объем стационарной помощи, измеренный числом койко-дней на одного жителя, сократился на 25,7\% (рисунок 1). Данные указывают, что пациенты перемещаются из стационара в поликлинику, а врачебные ресурсы в растущей степени концентрируются в стационаре, и наряду с этим сокращение коечного фонда больниц, предпринимаемое в последние годы, не сопровождается кадровым маневром - изменением соотношения врачебных кадров между поликлиниками и стационарами.

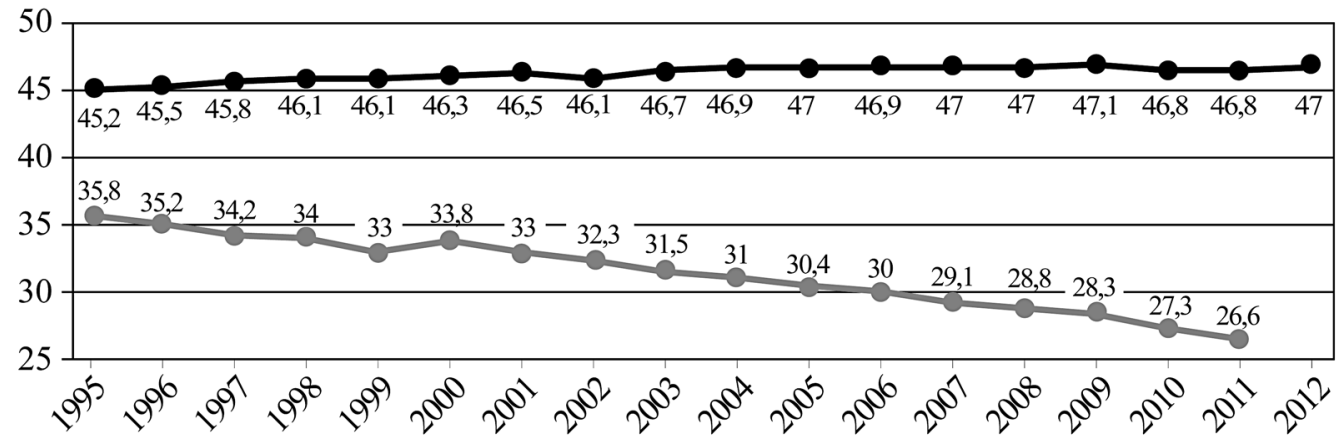

- удельный вес врачей стационара в общем числе врачей ЛПУ

—— число койко-дней на 10 жителей в год

Рисунок 1. Динамика доли занятых врачебных должностей стационарной службы в общем числе занятых врачебных должностей и объемов стационарной помощи ${ }^{3}$

В последние годы государство заметно активизировало кадровую и образовательную политику. Наиболее важным нормативным документом стало Распоряжение Правительства РФ от 15.04.2013 № 614-Р «О комплексе мер по обеспечению системы здравоохранения Российской Федерации медицинскими кадрами до 2018 года», в котором предусматривается изменение методики планирования кадров, повышение требований к вузовскому и постдипломному образованию, создание развитой системы аккредитации кадров и прочее, также растет понимание необходимости перехода от экстенсивного наращивания численности врачей к стратегии интенсивного развития с акцентом на оптимизацию их структуры.

В настоящее время в России в той или иной мере присутствуют все направления кадровой и образовательной политики, используемые в практике западных стран, но их масштабы и конкретные механизмы заметно различаются, а эффективность нового курса все еще невысока.

3 Рассчитано на основе отчетных форм Росстата № 30 «Сведения о сети и деятельности учреждений здравоохранения» и отчетных форм Минздрава России и ФФОМС № 62 «Сведения о реализации программы государственных гарантий оказания гражданам Российской Федерации бесплатной медицинской помощи». 


\section{Планирование медицинских кадров}

Можно выделить несколько важных различий в механизмах кадрового планирования в России и за рубежом, существенно искажающих оценку потребности в вузовской и послевузовской подготовке врачебных кадров. Во-первых, для определения дефицита специалистов используются данные о незаполненных вакансиях должностей, которые скрывают значительный уровень совместительства врачей, а следовательно, их высокую нагрузку: во многих регионах страны, например, участковые терапевты обслуживают участки в 3000-3500 чел. вместо 1700 чел. по федеральному нормативу. Формально свободных вакансий может быть немного, но фактически врачи перегружены, что негативно влияет на качество медицинской помощи. Такой подход приводит к явной недооценке дефицита врачей за счет игнорирования практики их совместительства и уже сложившейся перегрузки. По этой причине дефицит лучше оценивать путем сравнения фактического числа врачей и того их количества, которое требуется исходя из нормативов нагрузки одного врача.

Во-вторых, в России практически отсутствует перспективное планирование потребности в медицинских кадрах. Приказ Минздрава России от 24.06.2014 № 322 «О методике расчета потребности во врачебных кадрах» используется, как указано в документе, «для текущего планирования, выявления недостатка или избытка врачебных кадров». Такой подход не решает проблему структурных диспропорций кадровых ресурсов, поскольку их преодоление требует значительного времени; не решается и задача обоснования количественных параметров приема в вузы и подготовки врачей в ординатуре. Число планируемых мест при текущем планировании неизбежно ориентируется на достигнутые ранее показатели приема и возможности медицинских вузов, а не на перспективные потребности системы здравоохранения.

В-третьих, институты планирования медицинских кадров явно недостаточны для проведения детальной плановой работы по отдельным специальностям и профессионально-квалификационным группам. Плановая работа чрезмерно централизована, при этом роль регионов и профессионального сообщества невелика, также отсутствует процедура согласования федерального и региональных планов. Следует уточнить, что для профессионального сообщества оценки дефицита и профицита кадров и плановые показатели по отдельным специальностям, рассчитываемые Минздравом России, оказываются недоступными.

Наконец, сама методика планирования кадров, вопреки требованиям вышеупомянутого правительственного документа, учитывает только один фактор - планируемые объемы медицинской помощи. Результаты расчета потребности в кадрах по отдельным видам помощи во многом зависят от динамики объемов помощи (врачебных посещений, койко-дней и прочего). Принятые в последние три года варианты Программы государственных гарантий бесплатной медицинской помощи предусматривают стабилизацию объемов первичной медико-санитарной помощи (на уровне 9,2 врачебных посещений в год), что делает неизменными плановые оценки численности кадров первичной помощи. Такой подход искажает показатели потребности в кадрах первичной медицинской помощи и становится основой для воспроизведения существующего дефицита этих врачей ${ }^{4}$.

\footnotetext{
4 Аналогичные примеры можно привести и по другим врачебным специальностям.
} 
Методология планирования, основанная только на показателях объемов медицинской помощи, исключает оценку действия прочих факторов и поэтому порождает будущие диспропорции в подготовке кадров. Необходимо учитывать динамику заболеваемости населения, растущую потребность пациентов в сервисных характеристиках медицинской помощи (врач, работающий на двух должностях, не может уделить достаточно времени пациенту). Важно также учитывать сокращение объемов стационарной помощи, диктующее необходимость укрепления первичного звена здравоохранения. Происходящие в последние годы процессы оптимизации работы больниц могут быть оправданными только при условии, если они будут сопровождаться укреплением первичного звена здравоохранения, однако действующая методика планирования врачебных кадров игнорирует эти процессы.

Регулирование приема в медищинские вузы

Как и в большинстве западных стран, в России существует система квотирования приема в медицинские вузы. Постановление Правительства РФ от 27.03.2015 № 285 устанавливает регламент формирования контрольных цифр приема, в рамках которого осуществляется прием граждан на целевое обучение по договорам. В этом случае заказчиками выступают будущие работодатели студентов - органы управления здравоохранением регионов, некоторые федеральные ведомства. Совокупный заказ на подготовку врачей имеет тенденцию к росту с 39 тыс. чел. в 2006 г. до 52,3 тыс. в 2015 г. [Здравоохранение в России 2015].

Особенностью российского медицинского образования является ведомственная принадлежность большинства вузов: в системе Минздрава России числятся 46 медицинских высших учебных заведений и 15 учреждений последипломной подготовки; Минобрнауки России подведомственны 9 университетов, в составе которых есть медицинские факультеты.

Преимущественно ведомственная принадлежность медицинских вузов облегчает планирование приема студентов, но отнюдь не гарантирует обоснованность планов. Во-первых, как отмечалось выше, отсутствуют перспективные планы приема студентов для медицинских вузов: установление квот опирается только на текущие показатели, которые не отражают долговременную потребность во врачебных кадрах. Эти потребности могут существенно поменяться через 8 лет, необходимые для разработки контрольных цифр и обучения студентов. Во-вторых, контрольные цифры приема представляют собой не отражение реальной потребности рынка труда в кадрах той или иной специальности, а компромисс между запросом заказчика и предложением медицинского вуза, основанным на имеющихся ресурсах. В-третьих, процедура согласования контрольных цифр с регионами сводится к показателям целевого приема, т.е. к текущему планированию подготовки отдельных категорий специалистов. 


\section{Регулирование числа мест постдипломного образования}

Это направление структурной политики особенно важно, поскольку именно на этапе послевузовской подготовки закладывается будущая структура врачебных кадров. Если отдать решение этих вопросов самим медицинским вузам, то велика вероятность того, что структура врачебного корпуса будет отражать сложившуюся структуру предложения учебных кафедр безотносительно потребностей системы здравоохранения. В западных странах это давно осознали, поэтому правительства на Западе активно влияют на структуру мест по специальностям.

В России указанное направление регулирования явно ослаблено: Минобрнауки и Минздрав России устанавливают контрольные цифры приема в ординатуру, где ведется подготовка кадров по отдельным специальностям: терапии, хирургии, педиатрии, онкологии и прочее, - но эти цифры отражают прежде всего возможности медицинских вузов, и лучший пример этого - планирование подготовки кадров для участковой службы. Многократно в стратегических документах здравоохранения объявлялся приоритет подготовки врачей общей практики, однако практические действия по реализации этого курса определяются прежде всего структурой учебных кафедр медицинских вузов, уровнем понимания ректорами важности этого курса и готовностью брать на себя массовую подготовку врачей по данной специальности. Как следует из таблищы 2, более 70\% медицинских вузов, находящихся в ведении Минздрава России, либо совсем не имеют ординатуры по этой приоритетной специальности, либо принимают на это направление три и менее студентов в год. Агрегированные оценки показали, что доля мест обучения по общей врачебной практике от общего числа мест в системе последипломной подготовки России составляет всего 3\% против $18-48 \%$ в отдельных западных странах. Складывается ощущение, что государство никак не влияет на этот показатель, по существу отказываясь от собственных стратегических намерений.

Таблица 2. Доля медицинских вузов, реализующих программы ординатуры по специальности «общая врачебная практика» в 2016/2018 учебных годах

\begin{tabular}{|c|c|c|c|}
\hline & & $\begin{array}{l}\text { Число } \\
\text { вузов }\end{array}$ & $\begin{array}{l}\text { Доля от общего } \\
\text { числа вузов, \% }\end{array}$ \\
\hline \multicolumn{2}{|l|}{ Общее число медицинских вузов } & 49 & 100 \\
\hline \multirow{2}{*}{$\begin{array}{l}\text { Вузы, которые осуществили прием по специальности в } \\
\text { следующем объеме: }\end{array}$} & $1-4$ места & 30 & 61,2 \\
\hline & 5-10 мест & 6 & 12,3 \\
\hline \multicolumn{2}{|l|}{ Вузы, которые не осуществляли прием по специальности } & 13 & 26,5 \\
\hline
\end{tabular}

Источник: [Приказ Минздрава России № 322].

Руководители медицинских вузов практически сами устанавливают не только специальности врачей, но и методы их обучения, содержание которого определяется преподавателями исходя из уровня их компетенций. Причем квалификация 
педагогов далеко не всегда достаточна для того, чтобы подготовить специалистов высокого уровня. Кроме того, медицинские вузы оказались оторваны от своих клинических баз в ведущих клиниках. Как отмечают ведущие российские организаторы здравоохранения и врачи, не только студенты, но и кафедральные сотрудники становятся для больничных врачей «персонами нон грата», поскольку не занимаются активной лечебной работой. Недостаточная квалификация преподавателей и слабая связь образовательного процесса с клинической практикой превратились в острейшую проблему, требующую специального государственного регулирования [Печатников 2016; Ципенюк 2017]. Очевидно, что ее решение невозможно исключительно методами регулирования количественных параметров подготовки кадров: необходимо существенное повышение требований к подготовке врачей, а значит, и к профессиональному уровню преподавателей.

В последние два-три года появились признаки активизации регулирования медицинского образования с акцентом на постдипломное. В 2017 г. уже произошли серьезные изменения:

- впервые все выпускники клинических специальностей сразу по окончании вузовского обучения прошли первичную аккредитацию с получением квалификации врачей-терапевтов участковых и врачей-педиатров участковых, после чего они были допущены к работе на соответствующих должностях; большинство выпускников вузов могут поступать в ординатуру только после трехлетней работы в качестве участковых врачей; эта мера направлена на усиление практической направленности обучения врачей; одновременно делается попытка укрепить участковую службу путем притока новых специалистов;

- отменена интернатура, которая на протяжении многих лет представляла собой наиболее распространенную форму первичной последипломной специализации выпускников медицинских вузов на базе медицинских организаций под наблюдением преподавателей клинических кафедр и лечащих врачей медицинских организаций в течение года; после этого выпускники вузов имели право вести самостоятельную клиническую практику в соответствии с полученным сертификатом;

- внесены изменения в сроки обучения в ординатуре: если раньше вне зависимости от специальности оно продолжалось два года, по окончании которых врачи сдавали сертификационный экзамен и допускались к работе, то в настоящее время срок обучения дифференцирован по специальностям и составляет от одного до пяти лет;

- по окончании ординатуры врач должен получить первичную специализированную аккредитацию, предоставляющую право работать по специальности; в последующие годы проводится профессиональная переподготовка с соответствующей периодической аккредитацией (не реже одного раза в 5 лет);

- планируется увеличение доли мест в ординатуре по специальности «общая врачебная практика».

Некоторые из планируемых изменений во многом определяются острой нехваткой врачей участковой службы. Проблема, которая накапливалась десятилетиями, сегодня решается радикальными методами за счет принудительного направления выпускников в участковую службу без прохождения ординатуры. Возможно, это снизит остроту проблемы дефицита участковых врачей, но породит много других не менее острых проблем. Главные из них - (1) снижение требований к уровню 
подготовки врачей участковой службы: впервые в современной российской и международной практике вчерашние студенты сразу после университетской скамьи (без прохождения интернатуры и ординатуры) будут допущены к практической работе; (2) ослабление привлекательности работы в первичном звене здравоохранения для студентов и молодых врачей (велика вероятность того, что многие выпускники, испугавшись такого «доверия», вообще уйдут из медицины); (3) спад доверия населения к своему участковому врачу (и без того достаточно низкого); а самое главное - (4) ухудшение показателей здоровья тех пациентов, на которых будут «практиковаться» недоученные врачи.

Уместно заметить, что ни в одной европейской стране, ставящей задачу смягчения дефицита врачей первичного звена, эта задача не решается путем ослабления требований к длительности и качеству обучения: врачи приходят в первичное звено после нескольких лет обучения в ординатуре по специальности «общая врачебная практика». Государство регулирует этот процесс и предпринимает достаточно активные меры (в ряде стран - довольно жесткие) по привлечению выпускников вузов в общую врачебную практику. Нам представляется, что эта стратегия более оправдана, чем тактика «латания Тришкина кафтана», которая, похоже, возобладала в российской кадровой и образовательной политике.

\section{Регулирование внебюджетных мест}

В отличие от зарубежной практики в России государство не регулирует численность и структуру внебюджетных мест при приеме в ординатуру, их определяют сами медицинские вузы, что является питательной средой для формирования устойчивых диспропорций кадровых ресурсов. Вузы заинтересованы в обеспечении нагрузки преподавательских кадров и получении дополнительных доходов, поэтому на платной основе готовят врачей популярных специальностей, чья деятельность ориентирована преимущественно на платежеспособный спрос - стоматологов, дерматовенерологов, гинекологов, урологов и прочее: так, число бакалавров, специалистов и магистров по стоматологии выросло в период 2006-2015 гг. на $73 \%$, в то время как общее число студентов в медицинских вузах увеличилось лишь на 35\% [Здравоохранение в России 2015].

Медицинские вузы, сталкиваясь с проблемой недофинансирования, «добирают» финансовые средства прежде всего за счет «капитализируемых» профессий. Как следует из таблищы 3 , доля внебюджетного приема студентов по стоматологии составляет $72 \%$, по фармации - $62 \%$ (и это при очень высокой насыщенности рынка стоматологическими услугами и аптеками). Почти половина студентов, проходящих обучение по наиболее массовой специальности «лечебное дело», учатся на платной основе. Вполне очевидно, что большинство из них ориентированы на получение в будущем узких специальностей, приносящих высокий доход, однако им предстоит сложный путь поиска сначала места в ординатуре, а затем и места работы, поскольку спрос на гинекологов, урологов, косметологов, хирургов и иные популярные профессии очень незначителен, а менее популярные специальности вряд ли будут для них привлекательными. Иными словами, государство, не вмешиваясь в структуру внебюджетного приема, на практике поощряет будущие кадровые диспропорции. 
Таблица 3. Распределение численности студентов медицинских специальностей, обучающихся в специалитете, в зависимости от источников финансирования, 2016 г.

\begin{tabular}{|c|c|c|c|c|c|}
\hline \multirow[t]{2}{*}{ Специальность } & \multirow{2}{*}{$\begin{array}{c}\text { Всего } \\
\text { студентов } \\
\text { на всех } \\
\text { курсах, чел. }\end{array}$} & \multicolumn{2}{|c|}{$\begin{array}{c}\text { Обучающихся } \\
\text { за счет бюджетов } \\
\text { всех уровней }\end{array}$} & \multicolumn{2}{|c|}{$\begin{array}{c}\text { Обучающихся по договорам } \\
\text { об оказании платных } \\
\text { образовательных услуг }\end{array}$} \\
\hline & & чел. & $\%$ & чел. & $\%$ \\
\hline Лечебное дело & 142525 & 74970 & 52,6 & 6755 & 47,4 \\
\hline Педиатрия & 42383 & 29794 & 70,3 & 12589 & 29,7 \\
\hline Стоматология & 38900 & 10840 & 27,9 & 28060 & 72,1 \\
\hline $\begin{array}{l}\text { Медико-профилактическое } \\
\text { дело }\end{array}$ & 9212 & 7213 & 78,3 & 1999 & 21,7 \\
\hline Фармация & 28647 & 10910 & 38,1 & 17737 & 61,9 \\
\hline Медицинская биохимия & 2064 & 1340 & 64,9 & 724 & 35,1 \\
\hline Медицинская биофизика & 619 & 509 & 82,2 & 110 & 17,8 \\
\hline Медицинская кибернетика & 698 & 371 & 53,2 & 327 & 46,8 \\
\hline
\end{tabular}

Источник: данные раздела «2.1.2. Распределение численности студентов по курсам, направлениям подготовки и специальностям» сводной общероссийской таблицы по формам № BПО-1 за 2016 г. // http://минобрнауки.рф/министерство/статистика/информация-2016

В 2016 г. Минздрав России впервые ограничил количество мест для приема граждан по договорам с физическими и юридическими лицами для каждого из подведомственных учреждений, реализующих программы ординатуры [Приказ № 322 2016]. Это ограничение распространялось только на выпускников, завершивших освоение программ специалитета по новым образовательным стандартам высшего образования ${ }^{5}$.

\section{Выводы и рекомендации}

Анализ зарубежного опыта показывает, что в большинстве западных стран экстенсивное увеличение численности врачей и среднего медицинского персонала не исчерпывает проблематики кадрового обеспечения. Растущее значение приобретает стратегия структурных сдвигов, призванная обеспечить соответствие структуры кадров реальным потребностям отрасли в частности и общества в целом.

5 В 2016 г. это были выпускники стоматологических и фармацевтических факультетов. 
Кадровая политика (прежде всего новые подходы к планированию и регулированию структуры кадров) определяет содержание образовательной политики, которая решает не только проблемы собственно образовательного процесса, но и влияет на структурные параметры подготовки медицинских кадров, при этом усиливается взаимодействие этих направлений государственной политики.

В России структурная составляющая кадровой и образовательной политики оказалась ослабленной. Действующие методы планирования и регулирования кадров во многом воспроизводят структурные диспропорции кадрового состава отрасли, однако в последние годы предпринимаются попытки исправить положение, но результаты пока неочевидны. Базируясь на изучении зарубежного опыта, можно предложить восемь направлений деятельности.

1. Повысить акцент на структурные параметры кадровых ресурсов отрасли - ликвидацию сложившихся дефицитов и профицитов отдельных категорий врачей, прежде всего на ускоренное развитие кадрового обеспечения участковой службы, перемещение части врачебного персонала из стационара в поликлиники. Обеспечение этих и других структурных сдвигов должно стать основой системы прогнозирования и планирования кадров, регулирования подготовки и переподготовки медицинских кадров.

2. Изменить методику планирования численности врачебных кадров первичной медико-санитарной помощи. Предлагается планировать потребность во врачах в этом секторе здравоохранения не по объемам медицинской помощи (врачебным посещениям), а в расчете на одного жителя, основываясь на нормативах нагрузки врачей. Целесообразно планировать постепенное приближение к нормативу и его достижение в пределах 6-7 лет. В качестве контрольного индикатора целесообразнее ориентироваться на показатель численности обслуживаемого населения в сравнении с нормативами, при этом показатель укомплектованности должностей может дополнять этот главный показатель. Кроме того, при расчете численности врачей первичного звена следует также учитывать планируемое перемещение части случаев стационарной помощи на амбулаторный этап и необходимые для этого кадровые ресурсы в поликлиниках, для чего следует снижать нормативы нагрузки врачей первичного звена (число обслуживаемого населения) в соответствии с масштабами перемещения объемов стационарной помощи. При этом важно делать корректировку на наметившийся процесс повышения доли хронически больных и больных с множественными заболеваниями.

3. Устанавливать целевые показатели снижения разрыва в уровне обеспеченности врачами сельской и городской местности. На сегодняшний день этот разрыв очень велик и составляет 14,5 и 45,2 врачей соответственно на 10 тыс. жителей [Ресурсы и деятельность учреждений здравоохранения 2015]. Методика планирования кадров для сельской местности должна устанавливать сближение этих показателей как минимум до двукратного уровня.

4. Обеспечить разработку перспективного плана развития кадровых ресурсов. Текущее планирование кадров должно дополняться перспективным с расширением горизонта до 2030-2035 гг., для чего необходимо создать новую институциональную структуру планирования кадров. Недостатки планирования в России во многом определяются ограниченными ресурсами для проведения детальной плановой работы, чрезмерной централизацией планирования. С учетом изученного зарубежного опыта предлагается следующее: 
- в Минздраве России создать специальное подразделение по прогнозированию и планированию кадров; вменить в обязанность разработку детальных перспективных и текущих планов развития кадровых ресурсов в целом и по отдельным специальностям и профессионально-квалификационным группам;

- повысить роль регионального планирования: органы управления здравоохранением субъектов РФ должны формировать свои планы, причем с такой же степенью детализации, как и на федеральном уровне;

- создать процедуру согласования федерального и региональных планов;

- сделать обязательным привлечение профессионального сообщества к формированию планов кадровых ресурсов (особенно перспективных);

- обеспечить прозрачность планирования, что предполагает открытое предоставление не только общего подхода к планированию, но и конкретных алгоритмов расчетов и полученных результатов.

5. Усилить государственное регулирование структуры постдипломной подготовки кадров, обеспечить повышение доли выпускников медицинских вузов, проходящих ординатуру по специальности «общая врачебная практика». Альтернативой принудительному направлению выпускников в участковую службу являются повышение доли мест в ординатуре по общей врачебной практике (с 3 до 25-30\% в ближайшие 3-4 года), допуск к работе только после прохождения ординатуры, меры экономического стимулирования работы в качестве участкового врача, постепенный переход от терапевтической к общеврачебной модели участковой службы.

6. Усилить регулирование структуры приема на внебюджетные места в ординатуре. Предлагается внести поправки в закон «Об образовании», предусматривающие установление государственного регулирования приема студентов в ординатуру в медицинских вузах по специальностям на все места обучения независимо от источника его финансирования. Главный механизм этого регулирования - определение структуры ресурсов вузов по отдельным специальностям, в том числе состава учебных кафедр и профессорско-преподавательского состава, т.е. регулирование предложения образовательных услуг.

7. Повысить требования к качеству постдипломного образования. Необходимо разработать планы повышения сроков и углубления последипломной подготовки врачей с целью приближения к мировым стандартам обучения. В первую очередь это касается тех категорий специалистов, количество которых определяется как достаточное для удовлетворения потребности здравоохранения или даже отмечается определенный избыток. Число таких специалистов может быть сокращено, что даст возможность переориентировать ресурсы на углубление подготовки кадров; этот маневр ресурсами требует проведения тщательного анализа потребности здравоохранения в специалистах.

8. Изменить организачию аккредитации врачей. В зарубежном здравоохранении нормой является проведение аккредитации силами организаций профессионального сообщества, являющихся внешними по отношению к организациям, в которых ведется подготовка врачей. В России же проведение аккредитации возлагается на медицинские вузы, и поэтому ожидаемым результатом такой организации стала повсеместная аккредитация практически всех выпускников вузов, только что сдавших государственные экзамены в вузе, на базе которого проводилась аккредитация. 
Понимая, что выбор такой формы аккредитации диктуется прежде всего стремлением обеспечить устойчивый приток новых специалистов в систему здравоохранения, мы предлагаем начать работу по формированию новой системы аккредитации, способной более объективно оценивать компетенции врачей и отказываться от специалистов с уровнем подготовки, недостаточным для получения допуска к клинической работе. Рекомендуется по каждой специальности выделить центры передовой практики: лечебные отделения ведущих клинических больниц и институтов, кафедры медицинских вузов, зарекомендовавшие себя высокими результатами как учебной, так и клинической работы, другие организации профессионального сообщества; эти центры необходимо укрепить иностранными специалистами с высокой профессиональной репутацией. Возникающее в результате существенное повышение требований к аккредитации не должно быть одномоментным, его следует пролонгировать во времени и через 5-6 лет перейти к аккредитации на базе таких центров.

\section{Литература}

Здравоохранение в России (2015). Статистический сборник // Федеральная служба государственной статистики // http://www.gks.ru/bgd/regl/b15_34/Main.htm

Колосницына М.Г., Шейман И.М., Шишкин С.В. (ред.) (2009) Экономика здравоохранения. Учебник. М.: ВШЭ.

Печатников Л.М. (2016) Необходимо обеспечить людям доступность медицинской помощи // Московская медицина. № 6. С. 8.

Приказ Минобрнауки России от 27.01.2016 № 40 «Об утверждении общих объемов контрольных цифр приема по специальностям и направлениям подготовки (или) укрупненным группам специальностей и направлений подготовки для обучения по образовательным программам высшего образования за счет бюджетных ассигнований федерального бюджета на 2017/18 учебный год» // Garant.ru // http://www.garant.ru/products/ipo/prime/doc/71214834/

Приказ Минобрнауки России от 31.01.2014 № 78 «Об определении общих объемов контрольных цифр приема граждан по профессиям, специальностям и направлениям подготовки для обучения по имеющим государственную аккредитацию образовательным программам среднего профессионального и высшего образования за счет бюджетных ассигнований федерального бюджета в 2015 году» // Garant.ru // http://www.garant.ru/products/ipo/prime/doc/70482686/

Приказ Минобрнауки России от 26.03.2015 № 284 «Об утверждении общих объемов контрольных цифр приема для обучения по образовательным программам высшего образования за счет бюджетных ассигнований федерального бюджета на 2016/17 учебный год» // Garant.ru // http://www.garant.ru/products/ipo/prime/doc/70836280/

Приказ Минздрава России от 27.05.2016 № 322 «Об установлении квоты целевого приема для получения высшего образования за счет бюджетных ассигнований федерального бюджета по программам ординатуры в федеральных государственных организациях, находящихся в ведении Министерства здравоохранения Российской Федерации, на 2016 год» // Garant.ru // http://www.garant.ru/products/ipo/prime/doc/71312310/

«Противостояние логик»: врач, пациент и власть в условиях реформирования системы здравоохранения. Сводный аналитический отчет (2016) // Левада-Центр // М.: Левада-Центр.

Ресурсы и деятельность учреждений здравоохранения. За отдельные годы (2015)// Mednet.ru // http://mednet.ru/ru/statistika/deyatelnost-i-resursy-uchrezhdenij-zdravooxraneniya.html 
Скворцова В.И. (2012) Интервью министра здравоохранения РФ В.И. Скворцовой от 07.07.2012 // Эхо Москвы // http://echo.msk.ru/programs/beseda/903377-echo/

Ципенюк О. (2017) «Через 10-15 лет у нас образованных врачей в принципе не будет». Интервью с членом-корреспондентом РАН, главным урологом Минздрава России Д.Ю. Пушкарем // Коммерсантъ. 06.02.2017 // http://www.kommersant.ru/doc/3205843

Шейман И.М., Шевский В.И. (2014) Почему в России не хватает врачей? // Экономическая политика. № 3. С. 157-177.

Шейман И.М., Шевский В.И. (2015) Кадровая политика в здравоохранении: сравнительный анализ российской и международной практики // Вопросы государственного и муниципального управления. № 1. С. 143-167.

Шишкин С.В., Шейман И.М., Абдин А.А., Боярский С.Г., Сажина С.В. (2017) Российское здравоохранение в новых экономических условиях: вызовы и перспективы. М.: ВШЭ.

Batenburg R. (2015) Health Workforce Planning in Europe: Creating Learning Country Clusters // Health Policy, vol. 119, no 12, pp. 1537-1544.

Birch S., Kephart G., Murphy G.T., O’Brien-Pallas L., Alder R., MacKenzie A. (2009) Health Human Resources Planning and the Production of Health: Development of an Extended Analytical Framework for Needs-Based Health Human Resources Planning // Journal of Public Health Management Practice, November (Suppl), pp. 56-61.

Commission Staff Working Document on an Action Plan for the EU Health Workforce (2012) // European Commission, Strasbourg, 18.4.2012

Gauld R. (2015) Primary Healthcare as a Global Healthcare Concept // The Palgrave International Handbook of Healthcare Policy and Governance (eds. Kuhlmann E., Blank R.H., Bourgeault I.L., Wendt C.), Basingstoke: Palgrave Macmillan, pp. 69-84.

Health at a Glance: Europe. State of Health in the EU Cycle (2016) // OECD, Paris: OECD Publishing.

Health at a Glance 2017: OECD Indicators (2017) // OECD, Paris: OECD Publishing // http://proxylibrary.hse.ru:2155/10.1787/health_glance-2017-en

Kringos D.E., Boerma W.G.W., Hutchinson A., Saltman R. (eds.) (2015) Building Primary Care in a Changing Europe // The European Observatory on Health Systems and Health Policies // http://www.euro.who.int/en/about-us/partners/observatory/publications/studies/ building-primary-care-in-a-changing-europe-2015.

Kuhlmann E., Groenewegen P.P., Batenburg R., Larsen C. (2015) Health Human Resources Policy in Europe // The Palgrave International Handbook of Healthcare Policy and Governance (eds. Kuhlmann E., Blank R.H., Bourgeault I.L., Wendt C.), Basingstoke: Palgrave Macmillan, pp. 289-307.

Kuhlmann E., Larsen C. (2015) Why We Need Multi-level Health Workforce Governance: Case Studies from Nursing and Medicine in Germany // Health Policy, vol. 119, no 12, pp. 1636-1644.

Lafortune G. (2014) Health Workforce Planning and Mobility in OECD Countries, Bratislava: OECD.

Lafortune G., Moreira L. (2015) Trends in Supply of Doctors and Nurses in EU and OECD Countries. Expert Group Meeting on European Health Workforce. 16 November 2015, Brussels.

Macinko J., Starfield B., Shi L. (2003) The Contribution of Primary Care Providers to Health Outcomes within OECD Countries, 1970-1998 // Health Services Research, no 38, pp. 831-865.

Muth C., van den Akker M., Blom J., Mallen C., Rochon J., Schellevis F., Becker A., Beyer M., Gensichen J., Kirchner H., Perera R., Prados-Torres A., Scherer M., Thiem U., van den Bussche H., Glasziou P. (2014) The Ariadne Principles: How to Handle Multimorbidity in Primary Care Consultations // BMC Medicine, 12:223.

Ono T., Lafortune G., Schoenstein M. (2013) Health Workforce Planning in OECD Countries: A Review of 26 Projection Models from 18 Countries // OECD Health Working Papers, no 62, Paris: OECD Publishing.

Ono T., Schoenstein M., Buchan J. (2014) Geographic Imbalances in Doctor Supply and Policy Responses // OECD Health Working Papers, no 69, Paris: OECD Publishing.

Paris V., Devaux M., Wei L. (2010) Health Systems Institutional Characteristics: A Survey of 29 OECD Countries // OECD Health Working Papers, no 50, Paris: OECD Publishing. 
Sheiman I., Shevski V. (2017) Two Models of Primary Health Care Development: Russia vs Central and Eastern European Countries. Working paper. WP BRP 06/PSP/2017, Moscow: HSE.

Starfield B., Shi L., Macinko J. (2005) Contribution of Primary Care to Health Systems and Health // Milbank Quarterly, vol. 83, no 3, pp, 457-502.

\title{
Human Resource Policies in the System of Health Provision: Overcoming the Shortage of Physicians
}

\author{
I. SHEIMAN*, S. SAZHINA**
}

\begin{abstract}
*Igor Sheiman - PhD in Economics, Professor, Department of Health Care Administration and Economy, National Research University Higher School of Economics. Address: 20, Myasnitskaya St., Moscow, 101000, Russian Federation. E-mail: igor.sheim@g23.relcom.ru **Svetlana Sazhina - Leading Analyst, Centre for Health Policy, National Research University Higher School of Economics. Address: bldg. 2, 4, Slavyanskaya Sq., Moscow, 109074, Russian Federation. E-mail: ssazhina@hse.ru
\end{abstract}

Citation: Sheiman I., Sazhina S. (2018) Human Resource Policies in the System of Health Provision: Overcoming the Shortage of Physicians. Mir Rossii, vol. 27, no 3, pp. 130-153 (in Russian). DOI: 10.17323/1811-038X-2018-27-3-130-153

\begin{abstract}
This article analyses the interrelation between human resource policies and educational policies in the system of healthcare provision to solve the problem of the structural imbalance in the supply of physicians. International experience reveals a growing emphasis on policies which help maintain the optimal structure of medical workers, i.e. the structure that corresponds to the needs of the healthcare system and society as a whole. Such policies include new regulatory and planning mechanisms for medical schools, the regulation of admission plans and the specialization structure in postgraduate medical education, specific post-education employment practices, and measures to overcome the shortage of supply of some categories of physicians and their geographic misbalance. In Russia, the structural component of human resource policies and educational policies has clearly weakened. The current regulatory and planning methods tend to reproduce the accumulated structural imbalances. Regulatory measures to improve the quality of the training of physicians are still ineffective. No prospective planning exists. Postgraduate training is poorly oriented towards the specializations currently in short supply. Medical schools are interested in training physicians capable of paying for their education and the government does not have the instruments to manipulate the structure of the student body. Recent attempts to improve the situation have not resulted in any positive outcomes yet. The decision to accredit graduates for practicing in primary care without postgraduate
\end{abstract}


training will most likely deteriorate the quality of healthcare. Based on international experience, the authors suggest new regulatory mechanisms.

Key words: healthcare, human resource policy, education policy, medical education, physicians, post-graduate training

\section{References}

Batenburg R. (2015) Health Workforce Planning in Europe: Creating Learning Country Clusters. Health Policy, vol. 119, no 12, pp. 1537-1544.

Birch S., Kephart G., Murphy G.T., O'Brien-Pallas L., Alder R., MacKenzie A. (2009) Health Human Resources Planning and the Production of Health: Development of an Extended Analytical Framework for Needs-Based Health Human Resources Planning. Journal of Public Health Management Practice, November (Suppl), pp. 56-61.

Commission Staff Working Document on an Action Plan for the EU Health Workforce (2012). European Commission, Strasbourg, 18.4.2012.

Gauld R. (2015) Primary Healthcare as a Global Healthcare Concept. The Palgrave International Handbook of Healthcare Policy and Governance (eds. Kuhlmann E., Blank R.H., Bourgeault I.L., Wendt C.), Basingstoke: Palgrave Macmillan, pp. 69-84.

Health at a Glance: Europe. State of Health in the EU Cycle (2016). OECD, Paris: OECD Publishing. Health at a Glance 2017: OECD Indicators (2017). OECD, Paris: OECD Publishing. Available at: http://proxylibrary.hse.ru:2155/10.1787/health_glance-2017-en, accessed 31 May 2018.

Kolosnitsyna M., Sheiman I., Shiskin S. (eds.) (2009) Ekonomika zdravookhraneniya [Health Economics], Moscow: HSE.

Kringos D.E., Boerma W.G.W., Hutchinson A., Saltman R. (eds.) (2015) Building Primary Care in a Changing Europe. The European Observatory on Health Systems and Health Policies. Available at: http://www.euro.who.int/en/about-us/partners/observatory/publications/ studies/building-primary-care-in-a-changing-europe-2015, accessed 31 May 2018.

Kuhlmann E., Groenewegen P.P., Batenburg R., Larsen C. (2015) Health Human Resources Policy in Europe. The Palgrave International Handbook of Healthcare Policy and Governance (eds. Kuhlmann E., Blank R.H., Bourgeault I.L., Wendt C.), Basingstoke: Palgrave Macmillan, pp. 289-307.

Kuhlmann E., Larsen C. (2015) Why We Need Multi-level Health Workforce Governance: Case Studies from Nursing and Medicine in Germany. Health Policy, vol. 119, no 12, pp. 1636-1644.

Lafortune G. (2014) Health Workforce Planning and Mobility in OECD Countries, Bratislava: OECD.

Lafortune G., Moreira L. (2015) Trends in Supply of Doctors and Nurses in EU and OECD Countries. Expert Group Meeting on European Health Workforce. 16 November 2015, Brussels.

Macinko J., Starfield B., Shi L. (2003) The Contribution of Primary Care Providers to Health Outcomes within OECD Countries, 1970-1998. Health Services Research, no 38, pp. 831-865.

Muth C., van den Akker M., Blom J., Mallen C., Rochon J., Schellevis F., Becker A., Beyer M., Gensichen J., Kirchner H., Perera R., Prados-Torres A., Scherer M., Thiem U., van den Bussche H., Glasziou P. (2014) The Ariadne Principles: How to Handle Multimorbidity in Primary Care Consultations. BMC Medicine, 12:223.

Ono T., Lafortune G., Schoenstein M. (2013) Health Workforce Planning in OECD Countries: A Review of 26 Projection Models from 18 Countries. OECD Health Working Papers, no 62, Paris: OECD Publishing. 
Ono T., Schoenstein M., Buchan J. (2014) Geographic Imbalances in Doctor Supply and Policy Responses. OECD Health Working Papers, no 69, Paris: OECD Publishing.

Paris V., Devaux M., Wei L. (2010) Health Systems Institutional Characteristics: A Survey of 29 OECD Countries. OECD Health Working Papers, no 50, Paris: OECD Publishing.

Pechatnikov L. (2016) Neobkhodimo obespechit' lyudyam dostupnost' meditsinskoj pomoshchi [It is Necessary to Provide People with Access to Medical Care]. Moskovskaya meditsina, no 6, p. 8.

Prikaz Minobrnauki Rossii ot 27.01.2016 № 40 «Ob utverzhdenii obshchikh ob’emov kontrol'nykh tsifr priema po spetsial'nostjam i napravlenijam podgotovki (ili) ukrupnennym gruppam spetsial'nostej i napravlenij podgotovki dlya obucheniya po obrazovatel'nym programmam vysshego obrazovaniya za schet byudzhetnykh assignovanij federal'nogo byudzheta na 2017/18 uchebnyj god» [Order of the Ministry of Education and Science of the Russian Federation no. 40 dated January 27, 2016 "On the Approval of the Total Volume of the Admission Control Numbers for the Specialties and Areas of Training (or) Enlarged Groups of Specialties and Educational Directions to Training in Higher Education Programs at the Expense of Budget Allocations of the Federal Budget for the 2017/18 Academic Year"]. Garant.ru. Available at: http://www.garant.ru/products/ipo/prime/doc/71214834/, accessed 31 May 2018.

Prikaz Minobrnauki Rossii ot 31.01.2014 № 78 «Ob opredelenii obshchikh ob’emov kontrol'nykh tsifr priema grazhdan po professiyam, spetsial'nostyam i napravleniyam podgotovki dlya obuchenijya po imeyushhim gosudarstvennuyu akkreditatsiyu obrazovatel'nym programmam srednego professional'nogo i vysshego obrazovaniya za schet byudzhetnykh assignovanij federal'nogo byudzheta v 2015 godu» [Order of the Ministry of Education and Science of the Russian Federation no. 78 dated January 31, 2014 "On the Calculation of the Total Volume of the Admission Control Numbers of Citizens by Occupations, Specialties and Educational Directions to Training in Secondary Vocational Education and Higher Education Programs That Are Accredited by the State Through Budget Allocations of the Federal Budget in 2015"]. Garant.ru. Available at: http://www.garant.ru/products/ipo/prime/doc/70482686/, accessed 31 May 2018.

Prikaz Minobrnauki Rossii ot 26.03.2015 № 284 «Ob utverzhdenii obshchikh ob’emov kontrol'nykh tsifr priema dlya obucheniya po obrazovatel'nym programmam vysshego obrazovaniya za schet byudzhetnykh assignovanij federal'nogo byudzheta na 2016/17 uchebnyj god» [Order of the Ministry of Education and Science of the Russian Federation no. 284 dated March 26, 2015 "On the Approval of the Total Volume of the Admission Control Numbers for Training on Higher Education Programs at the Expense of Budget Allocations of the Federal Budget for 2016/17 Academic Year"]. Garant.ru. Available at: http://www.garant.ru/products/ipo/prime/doc/70836280/, accessed 31 May 2018.

Prikaz Minzdrava Rossii ot 27.05.2016 № 322 «Ob ustanovlenii kvoty tselevogo priema dlya polucheniya vysshego obrazovaniya za schet byudzhetnykh assignovanij federal'nogo byudzheta po programmam ordinatury $\mathrm{v}$ federal'nykh gosudarstvennykh organizatsiyakh, nakhodyashchikhsya $\mathrm{V}$ vedenii Ministerstva zdravoohraneniya Rossijskoj Federatsii, na 2016 god» [Order of the Ministry of Education and Science of the Russian Federation no. 322 dated May 27, 2016 "On the Establishment of a Quota for a Special Admission for Higher Education at the Expense of Budget Allocations of the Federal Budget for Residency Programs in Federal State Organizations Subordinated to the Ministry of Health of the Russian Federation for 2016"]. Garant.ru. Available at: http://www.garant.ru/products/ipo/prime/doc/71312310/, accessed 31 May 2018.

«Protivostoyanie logik»: vrach, patsient i vlast' v usloviyakh reformirovaniya sistemy zdravoohraneniya. Svodnyj analiticheskij otchet (2016) ['The Confrontation of the Logics': Physians, Patients and Authorities in the Context of the Healtcare System Reform. Consolidated Analytical Report]. Levada-Tsentr, Moscow: Levada-Tsentr.

Resursy i deyatel'nost' uchrezhdenij zdravookhraneniya. Za otdel'nye gody [Resources and Activities of Medical Facilities. Selected Years]. Mednet.ru. Available at: http://mednet.ru/ru/statistika/deyatelnost-i-resursy-uchrezhdenij-zdravooxraneniya.html, accessed 31 May 2018. 
Sheiman I., Shevski V. (2014) Pochemu v Rossii ne khvataet vrachej? [Why Does Russia Lack Physicians?]. Ekonomicheskaya politika, no 3, pp. 157-177.

Sheiman I., Shevski V. (2015) Kadrovaya politika v zdravookhranenii: sravnitel'nyj analiz rossijskoj i mezhdunarodnoj praktiki [Human Resource Policy in the Healthcare System: a Comparative Analysis of Russian and International Practices]. Voprosy gosudarstvennogo $i$ munitsipal'nogo upravleniya, no 1, pp. 143-167.

Sheiman I., Shevski V. (2017) Two Models of Primary Health Care Development: Russia vs Central and Eastern European Countries. Working paper. WP BRP 06/PSP/2017, Moscow: HSE.

Shishkin S., Sheiman I., Abdin A., Boyarsky S., Sazhina S. (2017) Rossijskoe zdravookhranenie $v$ novykh ekonomicheskikh usloviyakh: vyzovy i perspektivy [Russian Healthcare in the New Economic Environment: Challenges and Prospects], Moscow: HSE.

Skvortsova V. (2012) Interv'yu ministra zdravookhraneniya RF V.I. Skvortsovoj ot 07.07.2012 [Interview of the Minister of Health of the Russian Federation Veronica Skvortsova July 07, 2012]. Radio station "Ekho Moskvy". Available at: http://echo.msk.ru/programs/beseda/903377-echo/, accessed 31 May 2018.

Starfield B., Shi L., Macinko J. (2005) Contribution of Primary Care to Health Systems and Health. Milbank Quarterly, vol. 83, no 3, pp, 457-502.

Tsipenuk O. (2017) «Cherez 10-15 let u nas obrazovannykh vrachej v printsipe ne budet». Interv'yu s chlenom-korrespondentom RAN, glavnym urologom Minzdrava Rossii D.Yu. Pushkarem ["In 10-15 Years, There Won't Be Any Educated Physicians in Principle". Interview of the Corresponding Member of the Russian Academy of Sciences, Chief Urologist of the Ministry of Healthcare of the Russian Federation Dmitry Pushkar]. Kommersant, 06.02.2017. Available at: http://www.kommersant.ru/doc/3205843, accessed 31 May 2018.

Zdravookhranenie V Rossii (2015). Statisticheskij sbornik [Russian Healthcare. 2015. Statistical Bulletin]. Federal State Statistics Service. Available at: http://www.gks.ru/bgd/regl/b15_34/Main.htm, accessed 31 May 2018. 